\title{
ShamSol, Haroldino
}

\author{
Michel Sleiman
}

Desde o início, meu encontro com Haroldo de Campos pautou-se no interesse mútuo pelas questões próprias da poesia semítica e a ela relacionadas. Apresentei-me ao poeta em janeiro de 1990, no sobrado da Monte Alegre, com os rascunhos da minha tradução do penúltimo capítulo do Cântico dos Cânticos, feita a partir da versão árabe de 1909, por sua vez tradução bastante razoável de original grego. Na época HC tinha acabado de traduzir o Eclesiastes (Qohélet, $O$ Que-Sabe, 1990) e já começara a empresa de verter ao português a íntegra do Cântico, publicado por excertos e hoje finalmente reunido e incluso no Éden, um tríptico bíblico (2004: 113-138). A idéia em confrontar nossos textos era aquilatar realizações distintas para um mesmo poema, originadas a partir de configurações igualmente distintas — a hebraica e a árabe - de uma espécie de poema virtual cuja origem ancestre se perdia na linha do tempo. Partíamos dessa premissa: embora a conhecida cristalização hebraica legitime o poema enquanto tal dentro do legado hebraico-judeu maior, o Cântico, tanto na versão hebraica, como na tradução grega ou latina, deixa entrever outras realizações de linguagem, pálidas às vezes, mas não por isso menos significativas, dentre as quais o tinte árabe (fenício, caldaico) parecia plausível. Algo similar se dá com as medievais Mil e uma noites, que não borram de todo as marcas das versões anteriores, muito embora a fidedignidade do relato - tal qual o conhecemosao condicionamento árabe-islâmico das épocas em que foi escrito. De mais a mais, se é verdade que os poemas de nosso tempo resultam de confluências têmporo-espaciais múltiplas, não o é menos com relação aos antigos, especialmente no caso do árabe e do hebraico e suas respectivas e peculiares literaturas... se seus códigos não são afins na totalidade, aparentam-se, espiamse, mais do que poderia sugerir o olhar míope ou apressado. 
Anos mais tarde, à medida que eu avançava na transcriação de zejéis do andalusino Ibn-Quzmân, HC alternava a tradução de trechos bíblicos com a íntegra da Ilíada, que acabou publicada em 2001 e 2002. Víamo-nos pouco; às vezes com intervalo de anos, quando então se desenhou no último ano de vida do poeta o ensejo de traduzir algumas suras do Alcorão: ele a partir de traduções; e eu, do árabe. Nos poucos encontros que tivemos (o último já no hospital), lia para ele o texto árabe seguido da tradução, de versículo em versículo, ou por bloco, no caso de suras longas. Eram inevitáveis as interrupções da leitura: para apontar a coincidência fônica entre termos árabes e hebraicos, para marcar a semelhança da locução e, caso muitíssimo mais freqüente, para sublinhar a diferença radical entre os dois códigos no que se refere a seus respectivos sistemas lingüístico, poético e profético. De modo que HC tinha consciência da singularidade do Alcorão e do sistema retórico nele implícito, podendo diferenciar razoavelmente bem o que na tradução era do árabe e o que era da língua de chegada, muito embora o poeta ter buscado tal inflexão do idioma semita a partir do hebraico e do complexo de línguas em que se serviu para aceder ao acervo árabe: o francês, o alemão, o inglês, o espanhol etc. $\mathrm{O}$ interesse pela poesia dos árabes, incluída a de feição profética que $\mathrm{HC}$ entendia como marca consubstancial da cultura semítica como um todo, levou-o a cercar-se de múltiplos instrumentos facultadores da compreensão daquela cultura: dicionários, manuais lingüísticos, fitas cassetes, estudos generalizados sobre os antigos e os contemporêneos, especialmente da literatura - e em particular a poesia - , que ele conheceu através da pluma de um C. Middleton, A. Arberry, F. Corriente, dentre outros.

A "incursão transcorânica" de $\mathrm{HC}$, como o poeta se referia ao seu acercamento do Alcorão (vide fax anexo), pressupunha uma viagem ao tempo recuado dos egípcios e hebreus. De fato, não estava fora de suas prospecções a poesia dos antigos egípcios, da qual também nos deu algumas versões (ainda inéditas). No seu entender, certeiro, a palavra de Allah ao seu mensageiro Muhammad advinha de outros saaras além do hijāzico a oeste da Península Arábica. O Livro dos muçulmanos não está livre dos mitos de faraó, nem de influxos do helenismo, o que é de algum modo atestado no imaginário árabe medieval, profundamente impregnado, por exemplo, pelo signo vitorioso, e algo fantasmagórico, de Alexandre o Grande, a ostentar, "bicorne" (d̄ $\bar{u}$-alqarnayn), o troféu até então único da conquista de Oriente e Ocidente. Tais incursões de HC, 
no entanto, circunscrevem-se nos termos de um exercício que é "abordagem" especificamente "trans-luso-brasileira-corânica" (vide fax) válida para determinados signos do Livro de Allah convertidos em outros tantos do nosso idioma conforme certa concepção de poesia e de tradução de poesia, hoje bem conhecida nossa. A língua luso-brasileira lê a árabe através do francês e do inglês... mas, incursão, tal leitura deixa-se guiar por um conhecimento do campo árabe construído, por intuição e dedução, com base em experiências paralelas e mais sólidas do poeta, a saber, a sua lide com os Livros de Elohim, que levava aproximadamente duas décadas.

"Turgimão não-juramentado", o bem-humorado poeta olha o texto de Allah com a simpatia e a generosidade do amante da palavra posta a serviço da arte: "beleza pura", que a Allah certamente agrada: "Deus é belo e ama a beleza", deixou dito o Profeta. A simpatia de HC leva-o ao desafio, e a generosidade, à persistência. Sua mais feliz incursão transcorânica é a que empreendeu na tradução da Sura do Sol, capítulo XCI do Alcorão, que eu denomino ShamSol, em nova conjunção interlíngüe do astro-rei. A versão original me foi enviada por fax, no dia 22 de maio de 2003. Em seguida, trabalhei nela, ajustando a apresentação tipográfica e espacial, com base no que o poeta propunha, surpreso em descobrir que "o Alcorão presta-se à poesia tanto ou mais que a Bíblia... é vitamina pura", segundo o que me participou mais ou menos com essas palavras. O fascínio foi traduzido por perfeito paralelismo debuxado pelo poeta ao longo de seu texto, a assentar, cada qual no devido lugar, os sujeitos e referências aludidos na sura árabe: Deus, Suas criações, Seu enviado, os feitos e efeitos que protagonizam as coisas e seres criados e as relações do Enviado com os humanos bons e maus. HC traduziu a arquitetura implícita dessa sura em colunas que sugerem a cosmogonia de Deus-Allah em termos de uma escala descendente, representada, em ShamSol, da esquerda para a direita, na seguinte ordem: Deus, profeta, mundo, criaturas. Nas extremidades de tal esquema figuram os nomes e signos divinos ('āyatt) e, no meio, a coluna densa das ações e atributos, onde a vida terrena tem hora e vez e onde se enlaçam as paixões humanas com as forças e desígnios de Deus. O cosmos geométrico da sura podia finalmente ser exposto na página... proposição do poeta, que transforma o amálgama de idéias profundas do Alcorão em filigranas — de cores e tamanhos distintosperceptíveis ao olho, à razão e ao ouvido. Por fim, o poeta propõe um modo particular de sensibilizar os sentidos ocultos do Alcorão, uma espécie de 
conversão do bāṭin, palavra esotérica, em zạhir, palavra exotérica, segundo conhecida formulação do discurso profético-religioso (vide meu comentário na carta anexa). O recurso não olhou só as traduções francesa e inglesa, como também buscou a explicação, geralmente posta em notas de rodapé, transpondo-a para o discurso próprio do texto, como que a prescindir do famoso aparato das notas exegéticas. Dito de outro modo, ShamSol existe por si; é um ícone da língua brasílica a aglutinar a dicção árabe, tida não-raro por estranha, inacessível e pouco afinada com a nossa identidade. Se tal horizonte justifica a necessidade da tradução, o poema traduzido é horizonte vencido.

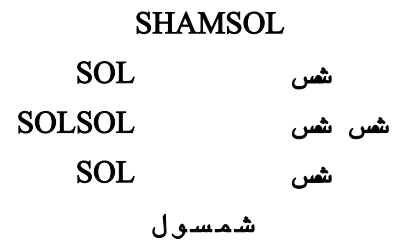

$\begin{array}{lll}\text { pelo } & \text { sol } & \text { e seu meio-dia de fogos coruscantes } \\ \text { pela } & \text { lua } & \text { que o segue qual ancila } \\ \text { pelo } & \text { dia } & \text { que manifesta o quanto ele radia } \\ \text { pela } & \text { noite } & \text { que obnubila o brilho de sua fronte } \\ \text { pelo } & \text { céu } & \text { e Quem o arquitetou } \\ \text { pela } & \text { terra } & \text { e Quem a faz distender-se } \\ \text { pela } & \text { alma } & \text { e Quem lhe deu a perfeição }\end{array}$

Aquele

que lhe atribuiu o pendor para o bem e para o mal

o que a soube guardar pura

este

goza de multiventura

o que a enegrece

este

já descambou no mal

os

tamūdīn

proclives ao crime

renegam o vero

ao mais perverso dentre eles

disse o 


$$
\text { núncio do céu "eis a fêmea de camelo que }
$$

Allah

fez exsurgir

do rochedo eis seu de beber"

trataram-no como falso profeta

mataram a miraculosa camela

Allah

Aquele-Que-É imune

a todo temor

fez cair sobre eles

a mão: arrasou-lhes

a cidade

Allah

não mede conseqüência

Fax de Haroldo de Campos, emitido em 22 de maio de 2003.

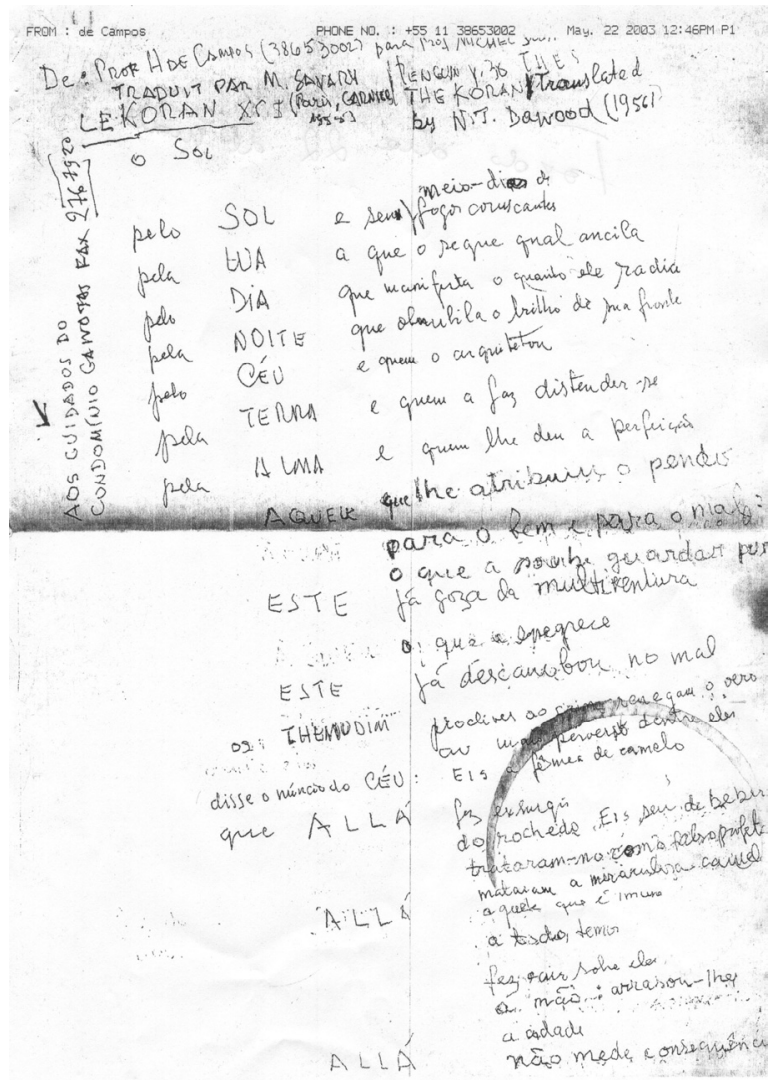


Carta-email, emitida em 23 de maio de 2003.

Caro Poeta Haroldo de Campos:

A sua lusotransluminação shamsolar irradia da mais estreita senda do Qur'ān, luzindo-lhe signos crístalo-cúficos dos mais recônditos (bātin).

O corpo constelar de seu ShamSol acorda da dormência a dança do cálamo dos primeiros calígrafos... pudera o perito da escritura permitir-se urdidura assim tão especular — que mão essa terá guiado o seu compasso, Haroldo, que matemática ordenado ao seu céu galático o insight plenilunar de mil e uma tardes coruscantes? - e tal perito nos legaria acrobacias. Aliás, dou-me conta agora de que não é outra coisa o desenho daquelas letras. Mas terá o iletrado Maomé submetido a razão a tais sinuosidades ou fora tudo desígnios de Allah? O-Ele-Ah sabe mais, é verdade, mas você bem que Lhe adivinhou o caminho.

Conferi a história da camela miraculosa: o seu "que Allah fez exsurgir do rochedo" é acréscimo. No entanto, de fato, Deus a fez exsurgir do rochedo. A alusão encontro no Tafsīr alqur'ān al'azīm, de Ibn-Katīir, morto em 774 H./1373 d.C., na página 237 do volume 4 da bela edição de Almanșūrah (1996) - capa verde dura, letras e arabescos dourados - que despachei do Cairo, junto com Mamede, incorporando nosso lote de 120 kg de livros abraâmicos; a capa diz ainda, na disposição vertical: alhậfiz Ibn-Kațīr "o guardião I.-K.", guardião da sabedoria das entrelinhas do Alcorão, que você recolhe e engasta no seu tiraz mallarmaico.

Você também está certo ao traduzir duhạa, no primeiro versículo, como "meio-dia de fogos coruscantes", e não como manhã, dia, ou claridade, como já se defendeu (vide os tradutores J. Cortés, espanhol, e A. Yusuf Ali, indiano), pois a idéia de claridade (ou manhã que rompe a noite), também prevista nos comentários do mesmo Ibn-Katīir e no Almuṣhaf almufassar, do genial Atțabarī, m. 310 H. (Cairo, 1993: 595), só é parcial; completam-na os sentidos de esplendor e grandiosidade, por oposição à escuridão das trevas. A hora dos fogos coruscantes denota bem o esplendor do astro rei, que aliás - e só menciono a título de lembrança-, no posto primício desta sura, rege os seguintes versículos em que se elencam seis das portentosas obras de Allah: lua, dia e noite, ao lado de céu, terra e alma, esta última a mais perfeita de Suas criações (por ser a única dentre elas a ter o livre-arbítrio de pender ao bem... ou ao mal, e com isso gerar o discurso de Allah?). 
Os seus "o que a soube guardar" e "o que a enegrece", valorados no contrapeso de dois "este", são outra z̧āhirização (sensibilização) do peso oculto das palavras do Alcorão. Não basta ao racional com anunciar-lhe a medida; há que mostrar-lhe as pedras do peso: 1 ESTE + 1 ESTE + 1 TAMŪDĪN num dos pratos da balança; e no outro 1 AQUELE + 1 NÚNCIO DO CÉU + 1 ALLAH (aqui ressalvo: se o trecho "que ALLAH fez exsurgir do rochedo" é explicitação sua de subtexto, maior compleição ainda é que conserve, em exemplar obediência ao princípio islâmico do $\underline{d i k r}$ [lembrança de Deus], a segunda menção do Seu nome ao optar — com acerto, proclame-se, dada a seara semântica desta sura- por "núncio do céu" onde quisera-se fosse "enviado de Allah").

Por fim, e não por último, a repetição, em três vezes, da partícula seqüencial e conclusiva $f a$ - — curta, seca e impressionantemente unívoca na referencialidade — você capta na solene e semítica (por hebraização sua pós-qohéletiana?) caracterização de Allah como "Aquele-Que-É imune a todo temor", seguida de duas ações, dadas na construção paralelística: "fez cair sobre eles" e "arrasou-lhes a cidade". Não conheço outra tradução dessa passagem que presentifique tão terrífica e imageticamente a ação de Allah, que o Texto árabe, senhor de si a todo momento, reduz ao abrupto $f a$-, e que você capitula no finalzinho do seu roteiro.

Como eu ainda dizia, o último estava por vir: o seu "não mede conseqüência" confere a Allah familiaridade poucas vezes conhecida entre Seus criados (a que esfera o levou Būrāq naquela noite?). No árabe, de fato, o texto reza: "não teme as conseqüências daquelas suas ações”, mas já sabemos, não é? Quem é imune a todo temor não precisa medir conseqüências... șadaqa llāhu l'azìm.

Receba um abraço de gratidão pelo que me toca essa sua homenagem.

Michel

São Paulo, 23 de maio de 2003. 
Fax de Haroldo de Campos, emitido em 26 de maio de 2003.

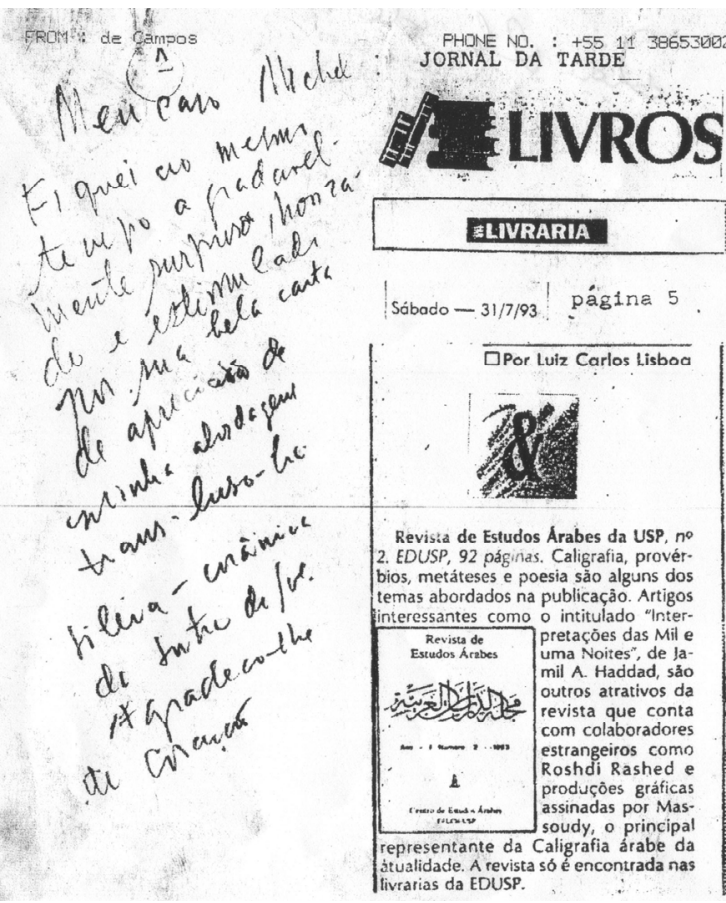

May. 262003 05:91PM P6

Mands the aqui. 1)

fecorte a Pad. Existem ainda lyeu flares e Revicla de Estuder tials da USt, coye 2: nop publime im 97. mencere sante a medar dc \& $c$ quen

1) Cumien IAYYUS

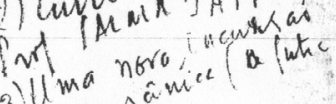
2) dl ma am

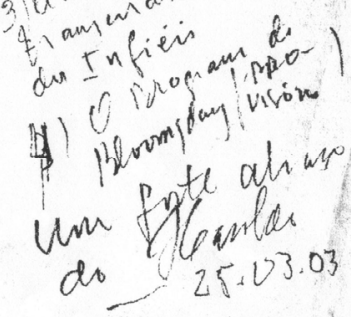

